\title{
N2 in the time of COVID-19
}

Neurol Neuroimmunol Neuroinflamm September 2020 vol. 7 no. 5 e858. doi:10.1212/NXI.0000000000000858

This issue of Neurology Neuroimmunology \& Neuroinflammation reflects the impact of the COVID-19 pandemic with 15 studies related to inflammatory or autoimmune neurologic complications in patients with this disease, including Guillain-Barré syndrome, CNS inflammatory disorders, and several studies addressing the risk of COVID-19 in patients with neuromyelitis optica spectrum disorders (NMOSD) or multiple sclerosis (MS). Among the latter, a study conducted in New York by Parotta et al. ${ }^{1}$ included 72 patients with MS (55 relapsing and 17 progressive) or related disorders (4 patients) and confirmed (37 patients) or suspected COVID19 illness. Most patients did not require hospitalization despite being on disease-modifying therapies; factors associated with critical illness were similar to those of the general at-risk patient population. On the other hand, most of the articles related to CNS disorders that occurred in association with COVID-19 are single cases describing acute necrotizing encephalitis or myelitis; acute disseminated encephalomyelitis; transient encephalitis with increased levels of interleukin 1 (IL1), IL6, and angiotensin-converting enzyme; and 2 cases of inflammatory vasculopathy (one of them with newly identified oligodendrocyte glycoprotein antibodies). Unrelated to the topic of the neurologic complications of COVID-19, the current issue of N2 contains multiple interesting studies, among which I selected 3 for additional comments.

In a retrospective study of pediatric patients with aquaporin 4 (AQP4) antibody-positive NMOSD performed in a center in Brazil and 13 European centers, Barbosa Paolilo et al. ${ }^{2}$ described the clinical phenotypes, treatment response, and outcome of 67 children. After a median follow-up of 4 years, $58 \%$ of patients had permanent disability, and those with non-White ethnicity had a worse expanded disability status scale (EDSS); these patients also had a shorter time from disease onset to first relapse. Overall, the most frequent phenotypes at disease onset were optic neuritis ( $45 \%$ bilateral), transverse myelitis, and isolated area postrema syndrome. CSF pleocytosis was present in $71 \%$ of patients. During follow-up, 297 attacks were assessed. Optic neuritis at disease onset was associated with poor visual outcome, and younger age at disease onset was associated with cognitive impairment. Several different treatments were used (azathioprine, mycophenolate mofetil, or rituximab), and all were associated with a reduction of annualized relapse rate. None of the children treated with rituximab as first-line immunotherapy had relapses. This study shows that AQP4-antibody NMOSD in children is an aggressive disease with permanent disability occurring in over $50 \%$ of patients. The study also shows that the approach to treatment varies according to investigators, centers, and countries, leading the authors to emphasize the need for international consensus on treatment protocols to minimize the heterogeneity of treatment regimens used worldwide.

In another study, Fujii et al. ${ }^{3}$ investigated whether patients with idiopathic painful trigeminal neuropathy (IPTN) had antibodies against Plexin D1 and whether the antibodies were able to bind trigeminal ganglion neurons. The rationale for this study is based in previous work of the same authors showing that about $10 \%$ of patients with neuropathic pain had antibodies against 
Plexin D1, which is a member of a family of transmembrane protein receptors that bind semaphorins as ligands. ${ }^{4}$ Plexin D1 was found expressed in endothelial cells, immunocytes, muscle cells, and small dorsal root ganglia (DRG) neurons. Patients with neuropathic pain and Plexin D1 antibodies frequently developed burning pain and thermal hyperalgesia along with sensory impairment, suggesting involvement of C-fiber type pain nerves and DRG neurons. ${ }^{4}$ In the current study, the authors investigated 21 consecutive patients with IPTN and 35 controls with neuropathic pain. Three (14\%) of the 21 patients had Plexin D1 antibodies; in addition to facial, perioral, and tongue pain or numbness, these patients also had limb or trunk neuropathic pain. The presence of tongue pain was more frequent than in Plexin D1 antibody-negative IPTN patients. Two of the patients received immunotherapy and one improved; the patient who did not improve had been symptomatic for 15 years, whereas the one who improved had symptoms for only a few months. Overall, this study shows that small subsets of patients with neuropathic pain or IPTN have Plexin D1 antibodies and that some of these patients can potentially improve with immunotherapy. Future studies with a larger number of patients are needed to better delineate the phenotype of these autoimmune neuropathic pain syndromes.

In another study, Pérez-Miralles et al. ${ }^{5}$ investigated the role of CSF chitinase 3-like-1 (CHI3L1), CHI3L2, and neurofilament light chain $(\mathrm{NfL})$ in predicting the course of primary progressive MS (PPMS). Twenty-five patients with disease duration $\leq 10$ years and without disease-modifying therapy for $\geq 6$ months were included in the study. The authors found that increasing CHI3L1 levels associated with higher EDSS scores at baseline and at month 12 and tended to be associated with a higher risk of disability progression. By contrast, increasing CHI3L2 levels tended to correlate with lower baseline EDSS scores, and no correlation was found with NfL levels. The authors acknowledge several limitations including the small sample size and short clinical follow-up (1 year); however, the study identified significant differences and tendencies that deserve confirmation in future investigations. Larger sample sizes and SIMOA technology, preferably in serum, are also needed to determine the role of NfL levels in patients with PPMS.

In addition to these studies, this September issue of N2 contains an excellent review on COVID-19 and Guillain-Barré syndrome by Dalakas ${ }^{6}$ and other interesting studies that I am sure will catch your attention.

\section{Study funding}

No targeted funding reported.

\section{Disclosure}

J. Dalmau holds patents for the use of Ma2, NMDAR, GABABR, GABAAR, DPPX, and IgLON5 as autoantibody tests and receives royalties from the use of these tests. He is editor of Neurology: Neuroimmunology \& Neuroinflammation. Go to Neurology.org/NN for full disclosures.

\section{References}

1. Parotta E, Kister I, Charvet L, et al. COVID-19 outcomes in MS: observational study of early experience from NYU Multiple Sclerosis Comprehensive Care Center. Neurol Neuroimmunol Neuroinflamm 2020;7:e835. doi: 10.1212/NXI. 0000000000000835.

2. Barbosa Paolilo R, Hacohen Y, Yazbeck E, et al. Treatment and outcome of aquaporin4 antibody-positive NMOSD: a multinational pediatric study. Neurol Neuroimmunol Neuroinflamm 2020;7:e837. doi: 10.1212/NXI.0000000000000837.

3. Fujii T, Yamasaki R, Miyachi Y, et al. Painful trigeminal neuropathy associated with anti-Plexin D1 antibody. Neurol Neuroimmunol Neuroinflamm 2020;7:e819. doi: 10. 1212/NXI.0000000000000819.

4. Fujii T, Yamasaki R, Iinuma K, et al. A novel autoantibody against Plexin D1 in patients with neuropathic pain. Ann Neurol 2018;84:208-224.

5. Pérez-Miralles F, Prefasi D, Garcia-Merino A. CSF chitinase 3-like-1 association with disability of primary progressive MS. Neurol Neuroimmunol Neuroinflamm 2020;7: e815. doi: 10.1212/NXI.0000000000000815.

6. Dalakas MC. Guillain-Barré syndrome: the first documented COVID-19-triggered autoimmune neurologic disease: more to come with myositis in the offing. Neurol Neuroimmunol Neuroinflamm 2020;7:e781. doi: 10.1212/NXI.0000000000000781. 


\section{Neurology \\ Neuroimmunology \& Neuroinflammation}

N2 in the time of COVID-19

Josep Dalmau

Neurol Neuroimmunol Neuroinflamm 2020;7;

DOI 10.1212/NXI.0000000000000858

This information is current as of August 20, 2020

\section{Updated Information \& Services}

References

Permissions \& Licensing

Reprints including high resolution figures, can be found at:

http://nn.neurology.org/content/7/5/e858.full.html

This article cites 6 articles, 4 of which you can access for free at: http://nn.neurology.org/content/7/5/e858.full.html\#\#ref-list-1

Information about reproducing this article in parts (figures,tables) or in its entirety can be found online at:

http://nn.neurology.org/misc/about.xhtml\#permissions

Information about ordering reprints can be found online: http://nn.neurology.org/misc/addir.xhtml\#reprintsus

Neurol Neuroimmunol Neuroinflamm is an official journal of the American Academy of Neurology.

Published since April 2014, it is an open-access, online-only, continuous publication journal. Copyright

Copyright (C) 2020 The Author(s). Published by Wolters Kluwer Health, Inc. on behalf of the American Academy of Neurology.. All rights reserved. Online ISSN: 2332-7812.

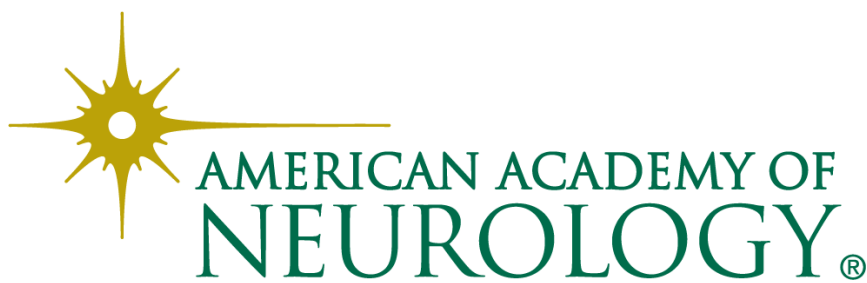

